East African Medical Journal Vol. 77 No. 2 February 2000

TESTICULAR CANCER AT KENYATTA NATIONAL HOSPITAL, NAIROBI

E.N. Opot, MBChB, MMed, and G.A.O. Magoha, FWACS, FICS, FMCS(Urol), Associate Professor and Chairman, Department of Surgery, College of Health Sciences, University of Nairobi, P.O. Box 19676, Nairobi.

Request for reprints to: Professor G.A.O. Magoha, Department. of Surgery, College of Health Sciences, University of Nairobi, P.O. Box 19676, Nairobi.

\title{
TESTICULAR CANCER AT KENYATTA NATIONAL HOSPITAL, NAIROBI
}

\author{
E.N. OPOT and G.A.O. MAGOHA
}

\begin{abstract}
Objective: To determine the prevalence, clinical characteristics, management methods and prognosis of testicular cancer at Kenyatta National Hospital.

Design: Retrospective case study of testicular cancer patients over a fifteen year period.

Setting: Kenyatta National Hospital, a referral and teaching hospital.

Participants: All histologically confirmed testicular cancer patients recorded at the Histopathology Department of Kenyatta National Hospital between 1983 and 1997.

Results: The mean age was 34.8 years with a peak incidence in the 30-44 year age group. History of cryptochirdism was obtained in $10.26 \%$ of the patients. Thirty one patients $\mathbf{7 9 . 4 9 \% )}$ presented with painless testicular swellings, eleven $(\mathbf{2 8 . 0 8 \%})$ with pain, nine $\mathbf{2 3 . 0 8 \%}$ ) with scrotal heaviness, six $(\mathbf{1 5 . 3 8 \%})$ with abdominal swellings and one $(\mathbf{2 . 5 6 \%})$ each with gynaecomastia and eye swelling. On examination 32 patients $(82.05 \%)$ had testicular masses, ten $(25.64 \%)$ had abdominal masses, seven $(\mathbf{1 7 . 9 1 \% )}$ ) had supraclavicular and cervical lymphadenopathy, and one each $(2.56 \%)$ had gynaecomastia and eye mass respectively. More than eighty nine per cent had germ cell cancers with seminoma accounting for $67.35 \%$, teratoma $12.24 \%$, embroyonal carcinoma $8.16 \%$, rhabdomyosarcoma $6.12 \%$ and malignant germ cell tumour, orchioblastoma and dysgerminoma each accounted for $\mathbf{2 . 0 4 \%}$. Three patients $(\mathbf{7 . 7 \%})$ had orchidectomy and radiotherapy and chemotherapy, sixteen $(41.03 \%)$ had orchidectomy and radiotherapy, six $(15.38 \%)$ had orchidectomy and chemotherapy, ten $(25.64 \%)$ had radiotherapy and chemotherapy, three $(\mathbf{7 . 7 \%})$ and two $(5.13 \%)$ had only chemotherapy and radiotherapy respectively. No cisplastin based chemotherapy regime was used. Follow up was effected for eighteen patients $(\mathbf{4 6 . 1 5 \%})$ and seven patients $(\mathbf{3 8 . 8 9 \%})$ were alive after five years.

Conclusion: Prognosis with current regimes was poor with survival of only $38.89 \%$ after five years. Cisplastin based chemotherapy with up to $90 \%$ cure rates should be included as a component of testicular cancer management at Kenyatta National Hospital.
\end{abstract}

\section{INTRODUCTION}

Testicular cancer is the most common malignancy in men between 15-35 years although it is rare in the general population(1). The cancer may appear at any age but tends to occur in three distinct age groups: infants and children (0-10 years), young adults (15-40 years) and older adults (over 60 years)(2,3). This tumour grows rapidly with a doubling time of 20-30 days and has a high risk of metastatic spread(4). The incidence of testicular cancer varies among different geographical regions and races $(5,6)$. Denmark had the highest incidence of about 4.9 per 100,000 annually(7). The white males in the United States and Western Europe have a high incidence of testis cancer, whereas Asians, Puerto Ricans, Africans and North American blacks have a low rate of testis cancer $(5,8,9)$. Approximately $95 \%$ of testicular tumours are of germ cell origin(10). Germ cell tumours are classically divided into seminomatous and non seminomatous cancers which include embryonal cell carcinoma, yolk sac carcinoma, choriocarcinoma and teratoma. Approximately $25 \%$ of testicular germ cell cancers are of multiple cell types with embryonal cell carcinoma and teratoma being the most common(11). Approximately $40-50 \%$ of patients with germ cell cancers have metastatic disease at presentation(2). Non germ cell tumours consist of 5-6\% of testicular tumours and include Leydig, sertoli, and granulosa cell tumours, smooth and skeletal muscle tumours, lymphomas, mesotheliomas, adenomatoid, mixed and incompletely differentiated tumours(13). Up to $90 \%$ of patients with testicular germ cell cancer will have elevated alpha fetoprotein (AFP) or beta human chorionic gonadotrophin (B-hCG)(14). Tumour markers are useful in the diagnosis, initial staging, assessing the response to therapy and early detection of relapse in germ cell cancers(15). Other less useful tumour markers include placental alkaline phosphatase (PLAP) which is elevated in 40-100\% of seminomas and serum lactase dehydrogenase isoenzyme 
(LDH-1) which is elevated in upto $60 \%$ of non seminomatous cancers $(13,16)$.

The most important risk factor associated with testicular cancer is cryptochirdism. Up to $10 \%$ of all patients with testicular cancer have a history of cryptochirdism(8). The incidence of cryptochirdism may be as high as $20 \%$ in premature males but is slightly less than $1 \%$ at one year of age(17). Martin found an increased incidence of testicular cancer with intrabdominal compared to inguinal testes and epidemiologic studies have shown that patients with cryptochirdism have 3-46 fold increased incidence of testicular cancer(18). Furthermore 5-10\% of patients with history of cryptochirdism develop malignancy in the contralateral normally descended testis(19). The second important risk factor in the development of testicular cancer is the presence of a contralateral tumour. Up to $5 \%$ of patients with testicular cancer will develop a contralateral testis cancer most often metachronously(20). Trauma, hormones such as diethylstilboestrol, and non specific mumps associated testicular atrophy have also been implicated as risk factors but there is very little data to support this(21-23). Testicular cancer has become one of the most curable solid tumours and serves as a model for multimodal treatment of malignancies. The dramatic improvement in survival resulting from combination of effective diagnostic techniques, effective multidrug chemotherapeutic regimens, and modification of surgical technique has led to a decrease in patient mortality from approximately $90 \%$ before 1970 to less than $10 \%$ in 1996(2,13).

\section{MATERIALS AND METHODS}

This was a retrospective case study of testicular cancer at Kenyatta National Hospital over a 15 year period (1983-1997). During this period 39 patients were seen and treated for testicular cancer. Ten other patients were originally seen with suspected testicular cancer at various peripheral hospitals in Kenya without histopathological facilities. For this group of patients, orchidectomy specimens were brought to Kenyatta National Hospital for the histopathological confirmation of testicular cancer diagnosis. Therefore a total of 49 cases of testicular cancer were recorded at $\mathrm{KNH}$ over the 15 year study period.

Data were collected from three sources. Case notes for the 39 patients were retrieved from the medical records department and additional information for this group of patients treated with either chemotherapy or radiotherapy was obtained from records at the radiotherapy department of the University of Nairobi at Kenyatta National Hospital. Histopathological confirmation of testicular cancer was confirmed with records at the department of histopathology at KNH. Relevant information regarding age, race, date of first presentation, geographic area of origin, past medical history, presenting symptoms, physical findings, histopathological confirmation of testicular cancer, haematological and routine blood chemistry, radiological investigations, the mode of treatment effected, and the clinical outcome of the various treatment regimes including follow up details was recorded. All surgical admissions at Kenyatta National Hospital for the fifteen year period was also recorded. These data was analysed and tabulated.

\section{RESULTS}

The yearly distribution of testicular cancer at Kenyatta National Hospital is illustrated in Table 1. There were 162768 surgical admissions over the 15 year period, but only 39 patients had testicular cancer representing only $0.02 \%$. The age range was $3-70$ years with a mean of 34.8 years and a peak incidence in the 30-44 year age group (Table 2). Previous history of cryptochirdism and tumour in the contralateral testis was reported in four patients $(10.26 \%)$, and two patients $(5.13 \%)$ respectively as illustrated in Table 3 . The various clinical symptoms are illustrated in Table 4 with the commonest being painless testicular swelling in 31 patients $(79.49 \%)$ being followed by testicular pain in 11 patients $(28.2 \%)$. The majority (thirty two patients) had testicular masses palpable on physical examination. Ten patients $(25.64 \%)$ had abdominal masses and seven patients (17.95\%) had enlarged supraclavicular and cervical lymph nodes, one patient $(2.56 \%)$ had orbital mass, another two patients $(5.13 \%)$ had chest wall masses and another one patient $(2.56 \%)$ had gynaecomastia (Table 5).

Table 1

Yearly distribution of testicular cancer at KNH

\begin{tabular}{cccc}
\hline Year & $\begin{array}{c}\text { No. of testicular } \\
\text { cancer patients }\end{array}$ & $\begin{array}{c}\text { Testicular cancer } \\
\text { specimens brought } \\
\text { for histopathology }\end{array}$ & $\begin{array}{c}\text { Total number } \\
\text { with testicular } \\
\text { cancer }\end{array}$ \\
\hline 1983 & 1 & 3 & 4 \\
1984 & 0 & 2 & 2 \\
1985 & 2 & 1 & 3 \\
1986 & 4 & 2 & 6 \\
1987 & 3 & 0 & 3 \\
1988 & 3 & 0 & 3 \\
1989 & 2 & 0 & 2 \\
1990 & 5 & 0 & 5 \\
1991 & 0 & 0 & 0 \\
1992 & 3 & 0 & 2 \\
1993 & 2 & 0 & 5 \\
1994 & 3 & 2 & 4 \\
1995 & 4 & 0 & 4 \\
1996 & 4 & 0 & 3 \\
1997 & 3 & 0 & 49 \\
\hline Total & 39 & 10 & \\
\hline
\end{tabular}

Table 2

Age distribution of testicular cancer patients at $\mathrm{KNH}$

\begin{tabular}{lcc}
\hline Age group in years & No. of patients & \% of total \\
\hline $0-14$ & 3 & 6.12 \\
$15-29$ & 16 & 32.65 \\
$30-44$ & 19 & 38.77 \\
$45-59$ & 7 & 14.29 \\
Over 59 & 4 & 8.16 \\
\hline Total & 49 & 100.0 \\
\hline
\end{tabular}


Table 3

Relevant past medical and surgical history in testicular cancer patients at $\mathrm{KNH}$

\begin{tabular}{lcc}
\hline Relevant history & No. of patients & \% of total \\
\hline Cryptochirdism & 4 & 10.26 \\
Orchidectomy for tumour & 2 & 5.13 \\
in contralateral testis & 1 & 2.56 \\
Trauma on same side & 3 & 5.13 \\
Laparotomy for intrabdominal mass & 2 & 5.13 \\
Hydrocelectomy on same side & 2 & 5.13 \\
Biopsy of unspecified testicular mass & 25 & 64.14 \\
No relevant history & 39 & 100.0 \\
\hline Total &
\end{tabular}

Table 4

Symptoms in testicular cancer patients at $\mathrm{KNH}$

\begin{tabular}{lcc}
\hline Symptom & No. of patients & \% of total \\
\hline Testicular swelling & 31 & 79.49 \\
Testicular pain & 11 & 28.20 \\
Scrotal heaviness & 9 & 23.08 \\
Abdominal swelling & 2 & 15.38 \\
Abdominal pain & 2 & 5.19 \\
Swelling on the chest & 2 & 5.19 \\
Perineal ulceration & 2 & 5.19 \\
Cough & 2 & 5.19 \\
Difficulty in breathing & 2 & 5.19 \\
Haemoptysis & 1 & 2.56 \\
Vomiting & 1 & 2.56 \\
Chest pain & 1 & 2.56 \\
Weight loss & 1 & 2.56 \\
Eye pain and swelling & 1 & 2.56 \\
\hline
\end{tabular}

Table 5

Physical signs in testicular cancer patients at KNH

\begin{tabular}{lcc}
\hline Physical sign & No. of patients & \% of total \\
\hline Scrotal/testicular mass & 32 & 82.05 \\
Abdominal mass & 10 & 25.64 \\
Supraclavicular and cervical lymph nodes & 7 & 17.90 \\
Weight loss & 3 & 7.69 \\
Testicular tenderness & 3 & 7.69 \\
Pleural effusion & 2 & 5.19 \\
Orbital mass & 1 & 2.56 \\
Chest wall mass & 2 & 5.13 \\
Scrotal ulceration & 1 & 2.56 \\
Gynaecomastia & 1 & 2.56 \\
\hline
\end{tabular}

Table 6

Histological types of testicular cancer at $\mathrm{KNH}$

\begin{tabular}{lcc}
\hline Histological type & No. of patients & \% of total \\
\hline Seminoma & 33 & 67.35 \\
Teratoma & 6 & 12.24 \\
Embryonal carcinoma & 4 & 8.16 \\
Malignant germ cell tumour & 1 & 2.04 \\
Rhabdomyosarcoma of paratesticular & 3 & 6.12 \\
adnexae & 1 & 2.04 \\
Orchioblastoma & 1 & 2.04 \\
Dysgerminoma & & 100 \\
\hline Total & 49 & \\
\hline
\end{tabular}

Table 7

Distribution of histological types of testicular cancer by age at KNH ( $n=49)$

\begin{tabular}{|c|c|c|c|c|c|c|c|}
\hline $\begin{array}{l}\text { Age group in } \\
\text { years }\end{array}$ & Seminoma & $\begin{array}{c}\text { Embryonal cell } \\
\text { carcinoma }\end{array}$ & Teratoma & Rhabdomyosarcoma & Dysgerminoma & Orchioblastoma & $\begin{array}{l}\text { Malignant cell } \\
\text { tumour }\end{array}$ \\
\hline $0-14$ & 1 & 1 & 0 & 0 & 1 & 1 & 0 \\
\hline $15-29$ & 6 & 2 & 6 & 2 & 0 & 0 & 0 \\
\hline $30-44$ & 16 & 0 & 0 & 1 & 0 & 0 & 1 \\
\hline $45-99$ & 7 & 0 & 0 & 0 & 0 & 0 & 0 \\
\hline $60-70$ & 3 & 1 & 0 & 0 & 0 & 1 & 0 \\
\hline Total & 33 & 4 & 6 & 3 & 1 & 1 & 1 \\
\hline Percentage & 67.35 & 8.16 & 12.24 & 6.12 & 2.04 & 2.04 & 2.04 \\
\hline
\end{tabular}


Table 8

Surgical procedures on testicular cancer patients at $\mathrm{KNH}$

\begin{tabular}{lcc}
\hline Surgical procedure & No. of patients & \% of total \\
\hline Inguinal orchidectomy & 21 & 53.84 \\
Scrotal Orchidectomy & 4 & 10.26 \\
Laparotomy & 4 & 10.26 \\
Lymph node biopsy & 4 & 10.26 \\
Incision biopsy of tumour & 3 & 7.69 \\
Enucleation of one eye & 1 & 2.56 \\
Chest tube and underwater seal drainage & 1 & 2.56 \\
\hline
\end{tabular}

Table 9

Various methods of treatment for testicular cancer patients at KNH $n=39$

\begin{tabular}{lcc}
\hline Modality of treatment & No. of patients & \% of total \\
\hline Orchidectomy radiotherapy and & 3 & 7.70 \\
Chemotherapy & 16 & 41.03 \\
Orchidectomy and radiotherapy & 6 & 15.38 \\
Orchidectomy and chemotherapy & 10 & 25.64 \\
Radiotherapy and chemotherapy & 3 & 7.7 \\
Chemotherapy alone & 2 & 5.13 \\
Radiotherapy alone & & \\
No treatment (patient died & 1 & 2.56 \\
soon after admission) & & \\
\hline
\end{tabular}

Histologically $89.8 \%$ of the cancers were of germ cell origin. Seminoma accounted for $67.35 \%$, teratoma for $12.24 \%$, embryonal carcinoma for $8.16 \%$, rhabdomyosarcoma of paratesticular adnexae for $6.12 \%$ and malignant germ cell tumour, orchioblastoma and dysgerminoma accounted for $2.04 \%$ each (Tables 6 and 7). The various surgical procedures effected on testicular cancer patients at $\mathrm{KNH}$ are illustrated on Table 8. Inguinal orchidectomy was performed on 21 patients $(53.84 \%)$, scrotal orchidectomy on four patients $(10.26 \%)$. Laparotomy on four patients $(10.26 \%)$, lymph node biopsy on four patients $(10.26 \%)$ and enucleation of the left eye on one patient $(2.56 \%)$. The various methods of treatment are illustrated on Table 9. Three patients $(7.7 \%)$ had multimodal therapy involving orchidectomy, radiotherapy and chemotherapy, 16 patients $(41.03 \%)$ had orchidectomy and radiotherapy, and six other patients $(15.38 \%)$ had orchidectomy and chemotherapy. Ten patients $25.64 \%$ had radiotherapy and chemotherapy, three patients $(7.7 \%)$ had only chemotherapy and two patients $(5.13 \%)$ had only radiotherapy. One patient $(2.56 \%)$ died within four days of admission and did not have any definitive treatment. Twenty one patients $(53.85 \%)$ were lost to follow up. Eighteen patients $(46.15 \%)$ were followed up. In this group eight patients $(44.44 \%)$ died within one year, and three other patients (16.67\%) died within 1-5 years. Seven patients $(38.89 \%)$ of the followed up patients were alive after five years.

\section{DISCUSSION}

The yearly distribution of testicular cancer (Table 1) indicates that over a 15 year period only 49 cases of testicular cancers were confirmed and recorded at Kenyatta National Hospital (KNH). Of these only 39 patients were actually seen and treated at KNH. The other 10 cases were for testicular specimens brought from various other parts of Kenya for histopathological diagnosis. These findings are similar to those of other investigators who have reported that testicular cancer is rare in Africans(5-6,9,24).

The age range was 3-70 years with a mean of 34.8 years and a peak incidence in the 30-44 year age group constituting $38.8 \%$ (Table 2). Similar findings were reported by Magoha in Lagos(6) and other investigators elsewhere(2,3). Four patients (10.26\%) had previous history of cryptochirdism. This is comparable with the findings of others who have reported that about $10 \%$ of all testicular cancer patients have a previous history of cryptochirdism(6,25-27), making it the single most important risk factor associated with testicular cancer. Two other patients $(5.13 \%)$ had previous history of testicular cancer in the contralateral testis. It has been previously reported that the second most important risk factor associated with testicular cancer development is the presence of a contralateral tumour. Up to $5 \%$ of patients with testicular cancer develop cancer in the contralateral testis $(19,28)$. Two patients $(5.13 \%)$ had previous history of hydrocelectomy and another patient had previous history of trauma on the same side. Recent literature has implicated minor inguinoscrotal traumatic events such as hydrocele repair, testicular trauma, hernia repair or vasectomy in the aetiology of testicular cancer(2,29,30).

Thirty one patients $(79.49 \%)$ presented with painless testicular swelling, eleven patients $(28.20 \%)$ had testicular pain, and nine patients $(23.08 \%)$ had scrotal heaviness. Eight patients $(20.5 \%)$ presented with respiratory symptoms of metastasis such as haemoptysis. Seven patients (17.95\%) presented with abdominal symptoms of metastasis, and one patient presented with eye symptoms of pain and swelling. It is a well known fact that the most common presentation of testicular cancer is a painless testicular swelling as reported in this study. Patients may also complain of fullness, dull ache, heaviness, pain and infertility(31). Testicular cancer may therefore be confused with epididymitis, orchitis, torsion, hydrocele, hernia, spermatocele or varicocele. About $50 \%$ of patients present with metastatic disease(12) and approximately $10 \%$ of the cancers will present with manifestations of metastatic disease(31) such as a neck mass from supraclavicular adenopathy, haemoptysis from lung metastasis, back pain from retroperitoneal adenopathy, bone pain from metastasis, gynaecomastia secondary to elevated serum beta human chorionic gonadotrophin(32), and gastrointestinal disturbances from direct or indirect involvement of tumour(33). The majority of patients in this study (64.1\%) presented with metastatic disease. The delay in diagnosis of 
testicular tumours is assumed to be correlated with a greater extent of metastatic spread through lymphatic and vascular pathways and subsequent higher stage of disease(34). The physical findings illustrated in Table 5 and largely corroborated the various symptoms in this study.

Germ cell cancers constituted $89.8 \%$ in this study. Testicular cancers are known to be of germ cell origin in 90.95\% of the cases and constitute the most common malignancy in men aged $18-35$ years $(34,35)$. Seminoma was reported in $(65.35 \%)$ of the patients, the majority of whom were in the 30-44 year age group (Tables 6 and 7). Seminoma is known to be the most common testicular cancer and accounts for approximately $60-65 \%$ of germ cell cancers $(2,36)$.

Most patients in this study had routine haematological and blood chemistry tests done. Tumour markers alpha fetoprotain (AFP) was estimated and found to be raised in fifteen patients $(36.46 \%)$; and beta human chorionic gonadotrophin (B-HCG) was estimated in one patient who presented with gynaecomastia. Up to $90 \%$ of testicular germ cell cancers have been reported to have elevated (AFP) or (B-HCG)(14). These tumour markers are useful in the diagnosis, initial staging, assessing the response to therapy and early detection of relapse in germ cell cancers(15). Radiological investigations done included chest X-rays in 20 patients $(51.28 \%)$ to rule out pulmonary metastases, abdominal and scrotal ultrasound on 18 patients (46.06\%), computer tomograms of the abdomen on four patients $(10.26 \%)$ and intravenous urogram on one patient $(2.56 \%)$. Scrotal and abdominal ultrasound is non invasive, radiation free and known to be highly accurate in the diagnosis of testicular cancer(37). Computer tomograms of the abdomen and chest are useful in the evaluation of retroperitoneal lymph nodes and chest metastases (38).

The management of testicular cancer depends on the clinical stage and the histological diagnosis although the initial treatment for most testicular tumours is orchidectomy. In this study, 21 patients had radical inguinal orchidectomy. The inguinal approach permits high division of the spermatic cord and early control of vascular and lymphatic supply as well as en block removal of the testis with all its tunics. It remains the definitive procedure for pathological diagnosis and local treatment of testicular cancer(39). Four patients (10.26\%) had transcrotal orchidectomy. Transcrotal biopsy of the testis when cancer is suspected is contraindicated and should be condemned(39). Following orchidectomy, patients should receive prophylactic abdominal irradiation because of the probable high rate of retroperitoneal metastases involving ipsilateral para-aortic and pelvic nodes(40). In this study three patients $(7.7 \%)$ had multimodal therapy including chemotherapy, radiotherapy and orchidectomy. Sixteen patients $(41.03 \%)$ had orchidectomy and chemotherapy. Ten patients $25.64 \%$ ) had chemotherapy and radiotherapy, three other patients had chemotherapy which included actinomycin-D, adriamycin, cyclophosphamide, vincristine and vinblastin. The most commonly used combination was vincristine, adriamycin and cyclophosphamide. It is not clear why cisplastin based chemotherapy which is much more effective was not used during the study period although the high cost may have been a factor. Two other patients $(5.13 \%)$ had radiotherapy alone, and no definitive treatment was affected for one patient who died from metastatic disease only four days after admission.

The prognosis of testicular cancer has improved dramatically even in advanced stages because of better staging techniques, reliable serum tumour markers and surgical resection after cytodestructive therapy. This combined multimodal approach using improved surgical techniques, radiotherapy and cisplastin based chemotherapy has resulted in cure rates of $80-90 \%$ in germ cell cancers(41). There is however controversy about the management of residual retroperitoneal mass after chemotherapy. The options for treatment of such masses include surveillance, surgical resection which is usually difficult because of dense desmoplastic changes induced by chemotherapy and radiotherapy(42). Twenty one patients $(53.85 \%)$ were lost to follow up. These patients were well on discharge but never returned either to surgical or radiotherapy clinics for follow up. Eighteen patients $(46.15 \%)$ were followed up for five years. Eleven patients $(61.11 \%)$ died during the follow up period, but seven patients $(38.89 \%)$ were alive after five years. These cure rates are much lower than those reported elsewhere $(2,13,41)$, and is due to the fact that no cisplastin based chemotherapy combination was used in this group probably due to its high cost. It is hoped that these results will encourage surgeons in this locality to insist on cisplastin based combination chemotherapy for testicular cancer irrespective of costs.

\section{REFERENCES}

1. Horwich, A. and Hendry W.F. Testicular tumours. Surg. 1988; 53:1266-1270.

2. Richie, J.P. Neoplasms of the testis. In Walsh, P.C. Retik, A.B. Vaughan, E.D. Jr., Wein, A.J. (eds): Campbells Urology 7th Edition 1998; 2411-2447 W.B. Saunders Co Philadelphia.

3. Mostofi, F.K. Testicular tumours. Epidemiologic aetiologic and pathologic features. Cancer 1973; 32:1186-1201.

4. Sagalowsky, A.L. Current consideration in the diagnosis and initial treatment of testicular cancer. Compr. Ther. 1994; 20:688690.

5. Daniels, J.L., Stutzman, R.E. and Mcleod, D.G. Comparison of testicular tumours in black and white patients. J. Urol. 1981;125:341-343.

6. Magoha, G.A.O. Testicular cancer in Nigerians. East Afr. Med. J. 1995; 72:554-556.

7. Osterlind, A. Diverging trends in incidence and mortality of testicular cancer in Denmark. Brit. J. Cancer 1986; 53:501-504.

8. Schottenfeld, D. Warshauer, M.E., Sherlock, S. et al. The epidemiology of testicular cancer in young adults. Amer. J. Epidemiol 1980; 112: 232 -236.

9. Oettle, A.G. Tumours of the testis in South Africa. The Leech XXXIV, 1964; 142 - 145.

10. Richie, J.P. Detection and treatment of testicular cancer. Ca. Cancer J. Clin. 1993; 43:151-175.

11. Rowland, R.G. Foster, R.S. and Donohue, J.P. Scrotum and testis. In Gillenwater J.Y., Grayhack, J.T., Howards, S.S., Duckett, 
J.W.(eds) Adult and Pediatric Urology, 3rd edition 1996; P.1917, Louis-Mosby Year book.

12. Sarosdy, M. Testicular cancer. An overview. In Crawford E.D., Das S(eds): Current genitourinary cancer surgery, 1999: P. 306. Philadelphia, Lea and Febiger.

13. Klein, E.A. and Levin, H.S. Non germ cell tumours of the testis. In Oesterling J.E: and Richie J.P. (EDS) Urologic oncology 1997; 496-514, W.B. Saunders Co.

14. Scardino, P.T. Cox, H.D. Waldman, T.A. et al. The value of serum tumour markers in staging and prognosis of germ cell tumours of the testis. J. Urol. 1977: 118: 994-996.

15. Javadpour, $\mathrm{N}$. The role of biologic tumour markers in testicular cancer. Cancer 1980a; 45:1755-1757.

16. Javadpour, N. Multiple biochemical tumour markers in testicular cancer. Cancer. 1983: 52:887-889.

17. Walker, R.D. Diagnosis and management of non palpable undescended testis. AUA Updates lesson 20(IX). Houston American urological association, 1992.

18. Martin, D.C. Malignancy in the cryptochird testis. Urol. Clin. North Amer. 1982; 9:371-376.

19. Bethelsen, J.G. Skakabeck, N.E., Sorensen, B.C. and Mogensen P.C. Screening for carcinoma in situ of contralateral testis in patients with germinal testicular cancer. Brit. Med. J. 1982; 285: $1283-1285$.

20. Dieckman, N.K., Boekmann, W. Brosig, W.et al. Bilateral testicular germ cell tumours: Report of nine cases and review of literature. Cancer 1986; 57:1254 -1256.

21. Swerdlow, A.J., Huttly, S.R.A. and Smith P.G. Is the incidence of testis cancer related to trauma or temperature? Brit. J. Urol. 1988; 128:56-58.

22. Gilbert, J.B. Tumours of the testis following mumps orchitis. Case report and review of 24 cases. J. Urol. 1944; 51:296-298.

23. Brouwn, L.M., Pottern, L.M. and Hoover, R.N. Prenatal and perinatal risk factors for testicular cancer. Cancer Res. 1986; 46:4812-4814.

24. Silverberg, C. Cancer statistics. Cancer. 1990; 40:9-12.

25. Abratt, R.P. Redi, V.B. and Sarembor, L.A. Testicular cancer and cryptochirdism. Brit. J. Urol. 1992; 70:656-658.

26. Batata, M.A. Chu F.C.H, Hiraris B.S.et al. Cancer. 1982;49:10231026.

27. Henderson B.E., Benton B., Jing J. et al. Risk factors for cancer of the testis in young men. J. Cancer 1979; 3:598-600.
28. Bokemeyer, C. Schmoll, H. Schoffski, P. et al. Bilateral testicular tumours: Prevalence and clinical implications. Eur. J. Cancer 1993; 6:874-876.

29. Strader, C.H., Weiss, N.S. and Daling, J.R. Vasectomy and incidence of testic cancer. Amer. J. Epidemiol. 1988; 128:58 -59.

30. Pike, M.C., Chilvers, C. and Peckham M.J. Effect of age at orchidopexy on the risk of testicular cancer. Lancet 1986; 1:12861288.

31. Bosl, G.J., Vogelzang, N.J. and Goldman, A. et al. Impact of delay in diagnosis on clinical stage of testicular cancer. Lancet 1981; 2:970-972.

32. Flood, J.G., Lighman, S.L. and Francis, S. Unusual presentation of a testicular tumour. Brit. J. Urol. 1991; 68:549-551.

33. Miller, T.T., Mendelson, D.S. and WU, L. et al. Seminoma of the testis presenting as an ulcerating mass of the duodenum. Clin. Imag. 1992; 16:201 -203.

34. Ulbright, T.M. Germ cell neoplasms of the testis. Am. J. Surg. Pathol 1993; 17:1075-1078.

35. Buetotow, S. Epidemiology of testicular cancer. Epidemiol Rev. 1995; 17:433-439.

36. Bredael, J.J. Vugrin, D. and Whitmore, W.F. Jr. Autopsy findings in 154 with germ cell tumours of the testis. Cancer 1982; 50:548 $-551$.

37. Richie, J.P. Birnholz, J. and Garnick, M.B. Ultrasonography as a diagnostic adjunct for the evaluation of masses in the scrotum. Surg. Gynaecol. Obstet 1982; 154:695-697.

38. Leibovitch, I. Foster, R.S. and Kopecky, K.K. et al. Improved accuracy of computarized tomography based on clinical staging in low stage non seminomatous germ cell cancer using size criteria of retroperitoneal lymph nodes. J. Urol. 1995; 154:1759-1762.

39. O'callaghan, A. and Mead, G.M. Progress in the management of solid tumours. Testicular carcinoma. Postgrad. Med. J. 1997; 73:481-486.

40. Lee, A.H.S., Mead, G.M. and Theaker, J.M. The value of central histopathological review of testicular tumours before treatment. Brit. J. Urol. Int. 1999; 84:75-78.

41. McCaffrey, J.A. Bajorin, D.F. and Motzer, R.J. Risk assessment for metastatic cancer. Urol. Clin. North. Am. 1998; 25: 389-395.

42. Ravi, R. Ong. J. R.T.D. Badenoch, D.F. Fowler, C.G. and Hendry, W.F. The management of residual mass after chemotherapy in metastatic seminoma. Brit. J. Urol. Int. 1999; 83:649-653. 